\title{
Complications of Breast Milk Application to the Infected Eye
}

\author{
CU Ukponmwan мввS, FMCOphth, FWACS; OT Okolo мввS; DH Kayoma мввS; Juliet Ese- \\ Onakewhor MввS
}

Dept of Ophthalmology, University of Benin Teaching Hospital, Benin City, Nigeria.

\section{SUMMARY}

Objective: To report complications resulting from the application of breast milk to the infected and injured eye seen at the University of Benin Teaching Hospital (UBTH) between June $1^{\text {st }} 2006$ and July $31^{\text {st }} 2007$.

Methodology: This is a prospective study of five consecutive patients who had breast milk applied to their eyes. They were seen at the eye clinic of the University of Benin Teaching Hospital between June $1^{\text {st }} 2006$ and July $31^{\text {st }} 2007$. The sex, age, symptoms and signs, visual acuity, treatment and ocular complications were noted.

Results: Four (80\%) of the patients developed complications following instillation of breast milk in the eyes. Two patients developed endophthalmitis, 1 for bacterial conjunctivitis and 1 for trauma; 1 patient developed panophthalmitis, and the fourth developed endophthalmitis. One child with bacterial conjunctivitis did not develop any complication.

Conclusion: Four out of the five patients studied lost vision in the affected eye after developing endophthalmitis and panophthalmitis following breast milk instillation in the infected and injured eyes.

Key words: breast milk, bacterial conjunctivitis, endophthalmitis, panophthalmitis, UBTH

\section{INTRODUCTION}

Breast milk has traditionally been used by mothers for many years to treat infectious conjunctivitis (pink eye). In rural areas, breast milk is used as eye drops in the treatment of viral conjunctivitis and as first aid in minor infections. It is inexpensive and readily available to nursing mothers.

Secretory immunoglobulin $\operatorname{Ig} \mathrm{A}$, which is present in colostrum and human milk, has been found to inhibit the adherence of bacteria to the mucosal surfaces and limits bacterial colonization of the eye..$^{1,2}$
The treatment of the pink eye depends on whether the infection is caused by a bacterium or a virus. Simple bacterial conjunctivitis is a very common and usually self-limiting condition, which resolves within 10 to 14 days even without treatment. $^{3}$ A bacterial infection should be treated with antibiotics to aid the resolution and treat any complication or associated keratitis. Viral conjunctivitis is also self limiting and should be treated to prevent complications. If breast milk is applied to an eye with viral conjunctivitis, the selflimiting nature of the infection convinces the mothers that the conjunctivitis resolved as a result of the breast milk application. The recent emphasis on exclusive breastfeeding in Nigeria and developing countries has made breast milk application to eyes with ocular problems more popular. ${ }^{4}$

Complications can occur from inappropriate application of breast milk to the eye in cases of bacterial conjunctivitis and ocular trauma. The aim of this study is to report the complications resulting from application of breast milk to the infected or injured eye and the management of such complications as seen at the University of Benin Teaching Hospital (UBTH) between June $1^{\text {st }} 2006$ and July $31^{\text {st }} 2007$.

\section{METHODOLOGY}

This is a prospective study of five consecutive patients who had breast milk applied to their eyes. They were seen at the eye clinic of the UBTH during the study period. The sex, age, symptoms and signs, visual acuity, treatment and ocular complications were noted.

\section{RESULTS}

\section{Case 1}

A fourteen-month-old female presented to the eye clinic with a history of gradual swelling of the left eye associated with pain and purulent discharge of 6 days duration. There was no history of trauma to or foreign body in the eye. Her mother applied breast milk to the eye and then noticed that the black part of the eye was white. She then applied genticin

*Correspondence: Dr Catherine U. Ukponmwan, Department of Ophthalmology, University of Benin Teaching Hospital, Benin City, Nigeria. • E-mail: kateukponmwan@yahoo.com 
eye drops and gave the infant ampiclox syrup. On examination, the left eyelids were oedematous, the conjunctiva was injected and there was a stromal abscess involving the whole cornea. Visual acuity could not be assessed because the child was uncooperative. A diagnosis of panophthalmitis of the left eye was made. She was admitted and an eye swab was taken for microscopy, culture and sensitivity. She was put on intravenous ceftraxone $500 \mathrm{mg}$ bd for 48 hours, then changed to oral ceftraxone, gutt atropine, gutt ciprofloxacin, fortified genticin, chloramphenicol ointment and subconjunctival injections of genticin and ceftazidine. Ketoconazole tablets and gutt fluconazole were added later.

Microscopy showed both gram positive cocci and gram negative bacilli, but the culture yielded no growth. The eye became staphylomatous on the second day of admission. The patient was admitted in the hospital for twelve days and discharged from the hospital on request to continue the treatment at home. On the last follow-up visit to the clinic, the stromal abscess had resolved with a corneal opacity involving the whole cornea, and the eye was staphylomatous. Figure 1 shows the eye with panophthalmitis.

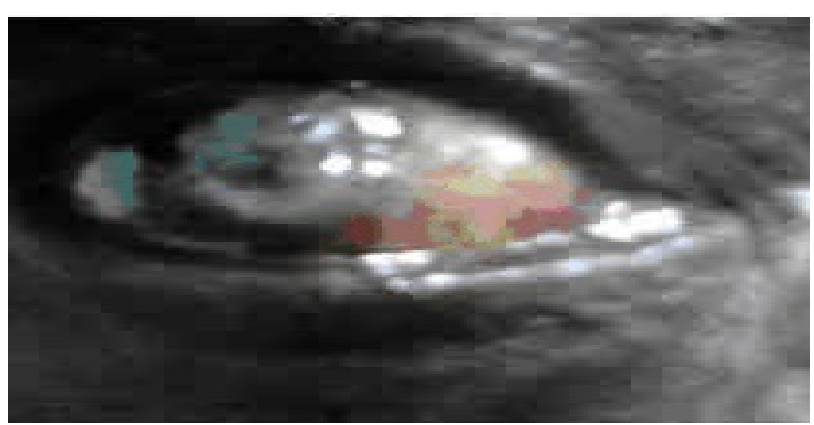

Fig 1. Panophthalmitis secondary to breast milk application

\section{Case 2}

$\mathrm{OE}$, a 35-year-old female farmer presented to our eye clinic with a 9-day history of redness, photophobia, pain and epiphora of the right eye and loss of vision in the eye of 7 days duration. This occurred after trauma to the eye by a palm kernel missile that came off a kernel cracking machine. She applied breast milk (from her mate) to the eye on the first day, pepper soup spices on the second day and traditional eye medications from leaves and other concoctions on the third day. When she noticed that she could no longer see with the affected eye, she went to a general hospital on the fifth day where she was placed on gutt ciprofloxacin and then referred to UBTH. She did not come until the ninth day after the injury.
On examination, visual acuity was light perception in the right eye and $6 / 5$ in the left eye. The right eyelids were oedematous, the conjunctiva was injected and there was an extensive corneal ulcer with a stromal abscess and hypopyon. A diagnosis of keratitis secondary to trauma and traditional eye medication was made. She was admitted and commenced on gutt lomefloxacin 2 hourly, gutt atropine, fortified genticin and canesten ointment, oral ciprofloxacin $500 \mathrm{mg}$ bd, diclofenac tablets, ketoconazole tablets, vitamin C tablet. Subconjunctival injection of genticin, ceftazidine, intravitreal ceftazidine and genticin injection were also given. There was no improvement in the eye and it progressed to panophthalmitis (fig. 2). The eye was eviscerated on the $13^{\text {th }}$ day of admission and she was subsequently discharged.

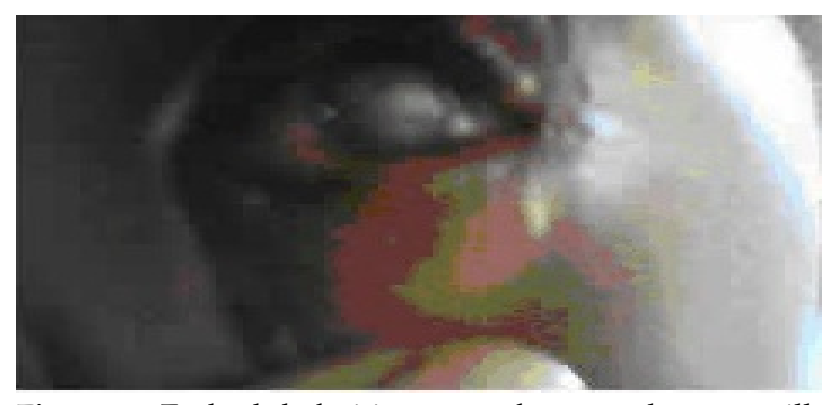

Fig 2. Endophthalmitis, secondary to breast milk application

\section{Case 3}

JB, a $2 \frac{1}{2}$ year-old female presented to the eye clinic in May 2007 with a two-day history of trauma to the right eye. A classmate poked an iron rod into the eye. There was discharge of clear fluid from the eye but there was no bleeding. The mother applied breast milk to the eye and genticin eye drops the next day. On examination, visual acuity was no light perception. The eyelids were oedematous, the conjunctiva was injected and there was purulent discharge. The cornea was perforated, there was a mucus plug and stromal abscess. There was hypopyon in the anterior chamber. The other ocular structures could not be visualized. The left eye was normal. An diagnosis of endophthalmitis secondary to trauma was made. She was admitted and an eye swab was taken for microscopy, culture and sensitivity. She was placed on chloramphenicol ointment, ciprofloxacin, fortified genticin, fluconazole and atropine eye drops. Subconjunctival injection of genticin $40 \mathrm{mg}$ daily, Zinnat suspension, Ibuprofen syrup and vitamin $C$ syrup were added. The microscopy showed gram positive cocci, gram negative bacilli and the culture yielded a growth of Escherichia coli and Candida species. The organism was sensitive to augmentin, cefuroxime and ceftazidime. The 
drugs were changed to subconjunctival injection, ceftazidime 100mg daily, lomefloxacin eye drops and fluconazole suspension. Endophthalmitis resolved after 4 weeks of admission and she was discharged from the hospital, but the eye was phthisical. The mother was a housewife who had a junior secondary school certificate while the father was a farmer with no formal education.

\section{Case 4}

FI, a two-year-old male presented to the eye clinic in June 2007 with a 2-day history of redness, pain and a 1-day history of discharge in the right eye. There was no history of trauma. The mother applied breast milk to the eye. She also applied chloramphenicol eye drops the next day, but there was no improvement. The discharge increased and was purulent. She then brought him to hospital. On examination the visual acuity could not be assessed because the child was uncooperative. The eyelids were oedematous, the conjunctiva was injected and chemosed. There was purulent discharge. The cornea was hazy, but did not stain with flourescein. There was hypopyon and the other ocular structures were not visualised. A diagnosis of endophthalmitis in the right eye was made. He was admitted and commenced on gutt lomefloxacin, gutt atropine, gutt fluconazole and oc. chloramphenicol, subconjunctival injection of genticin and intravenous ceftraxone.

Microsocopy of the conjunctival discharge showed gram positive cocci, but the culture yielded no growth. He was discharged from the hospital on the $4^{\text {th }}$ day and treatment was continued on daily outpatient basis. A week later, the cornea was still hazy, but the hypopyon was resolving. He was to be readmitted and to have intravitreal antibiotics, but his mother refused and the patient defaulted from the clinic. He was then lost to follow up. Both parents were traders with primary school education.

\section{Case 5}

A three-month old male presented to the eye clinic in July 2007, with a three-month history of purulent discharge in the right eye. The discharge was first noticed at birth. The mother applied breast milk before presenting to a private eye clinic where chloramphenicol eye drop was prescribed. There was no improvement, the patient then presented to UBTH. On examination, the adnexae was normal, the conjunctiva was injected with copious purulent discharge. The cornea was clear and all the other structures were normal. A diagnosis of bacterial conjunctivitis was made and he was placed on ciprofloxacin eye drops, oxytetracycline ointment and augmentin suspension. The infection had resolved when he was seen in the clinic 2 weeks later.
Table 1. Showing demographic data and ocular complications

\begin{tabular}{lllll}
\hline Patients & Sex & Age & Diagnosis & Complications \\
\hline Case 1 & Female & 14 months & Conjunctivitis & Panophthalmitis \\
Case 2 & Female & $35 \mathrm{yrs}$ & Trauma & Panophthalmitis \\
Case 3 & Male & $2 \mathrm{yrs}$ & Conjunctivitis & Endophthalmitis \\
Case 4 & Female & $2.5 \mathrm{yrs}$ & Trauma & $\begin{array}{l}\text { Endophthalmitis, } \\
\text { phthisis bulbi }\end{array}$ \\
Case 5 & Male & 3 months & $\begin{array}{l}\text { Bacterial } \\
\text { conjunctivitis }\end{array}$ & None \\
\hline
\end{tabular}

\section{DISCUSSION}

These case reports reveal the ocular complications which can occur following application of breast milk to an infected or injured eye. Children are more at risk than adults because their mothers may be lactating and breastfeeding either the child or a sibling, and so find breast milk readily available. Breast milk has traditionally been used for treatment of the pink eye, but the eye may be infected with bacterial, viral or fungal organisms that are not sensitive to the antibodies in breast milk. The recent emphasis on exclusive breastfeeding by WHO (Baby Friendly Initiative) has further aggravated the situation because mothers are encouraged to breastfeed their babies exclusively with breast milk for the first 6 months and are educated on the contents and advantages of breast feeding. ${ }^{4}$ They believe that breast milk can be used in the treatment of diseases. It is also readily available. Human breast milk contains antibacterial factors such as immunoglobulin A, lactoferrin, lysozyme, oligosaccharides, macrophages, lymphocytes, protease inhibitors, complement, interferon, oligosaccharides, B12 binding, antistaphylococcus, ${ }^{5}$ but the organisms in the infected eye may be resistant to these factors and so complications may occur if breast milk is used exclusively for the treatment of the ocular infection.

Breast milk contains significantly more lactose than cow's milk ${ }^{6}$ and this may also stimulate the growth of microorganisms. The concomitant use of other types of traditional eye medications may aggravate the problem as in case 2, where the patient used other types of traditional eye medications in addition to breast milk. Four (80\%) out of the five (5) patients in this study were seen within a short period of three months. Four of them were children and only one was an adult. Four of these cases developed endophthalmitis and panophthalmitis and subsequently lost vision in the affected eyes. The adult female had evisceration of the eye. Only the last patient (case 5) retained his vision and his eye. Two of the cases were secondary to trauma while the remaining three were bacterial and fungal keratoconjunctivitis. Trauma to the eye is an ocular 
emergency that should be referred promptly to the ophthalmologist.

Delay in presentation to the hospital in cases of the injured eye has been shown to worsen the prognosis. ${ }^{7}$ The application of breast milk caused a delay in presentation to the hospital and further worsened the prognosis. The prognosis of the initial lesion in cases of an injured eye is adversely affected by delay before proper management or presentation to a hospital and by administration of inappropriate home medication. ${ }^{7}$ A study in Tanzania showed that breast milk is frequently mixed with other herbal or powder concoctions in the treatment of the injured eye while another study in the rural areas of southern India on the use of traditional eye medications in the treatment of corneal ulcers, showed that $45.2 \%$ of the patients used breast milk. ${ }^{8,9}$ There are articles on the internet encouraging mothers to use breast milk in the treatment of the pink eye, ${ }^{1,2}$ but this should be discouraged in a developing country like Nigeria because most parents cannot differentiate a bacterial conjunctivitis from a viral conjunctivitis and are likely to use it on the injured eye as shown in this study. Breast milk has been shown to be contaminated by anaerobic bacteria. ${ }^{10}$

Some viruses such as the human immunodeficiency virus and the West Nile virus have been shown to be present in breast milk. ${ }^{11,12}$ Complications such as keratitis, endophthalmitis and panophthalmitis have been reported to occur from the use of traditional eye medications. ${ }^{8,9,13}$ These complications have also been shown in this study where four out of five patients developed endophthalmitis and panophthalmitis from the use of breast milk. The female patient (Case 2) also applied herbal preparations and other types of traditional eye medications to her injured eye. In a study on corneal ulceration in Benin City, panophthalmitis and corneal perforation developed in 12 out of 15 eyes where traditional medication was used prior to presentation. ${ }^{14}$ Courtright ${ }^{15}$ reported that $33.8 \%$ of patients with corneal disease who presented to district hospitals in rural Malawi had already used traditional eye medications. Peripheral corneal ulcers have been associated with the use of traditional eye medications. ${ }^{16}$ The use of harmful traditional eye medications have been reported in epidermic of acute haemorrhagic conjunctivitis in Africa. ${ }^{17}$ Chirambo et al. ${ }^{18}$ attributed $26 \%$ of blindness among school children to the use of traditional eye medication. A study by Yorsten and Forster $^{19}$ in Tanzania revealed that $25 \%$ of corneal ulcers in 103 patients was associated with the use of traditional eye medications within the previous seven days.

The use of breast milk in the treatment of the inflamed or injured eye should be strongly discouraged. There should be intensive health education through the mass media and the Internet on the complications and dangerous effects of traditional eye medications, including breast milk to the eye.

\section{REFERENCES}

1. Natural pink eye drops use in babies. In: Baby Health. By Baby First Year

2. The Healing Power of Breast milk. In Pregnancy Info. net http://www.pregnancy-info.net/breastfeeding_illness.html

3. Kanski JJ. Clinical Ophthalmology, A Systematic Approach. $6^{\text {th }}$ ed. Edinburgh, London: Butterworth Heinemann Elsevier. 2007; 219-226.

4. WHO/UNICEF. The Innocent Declaration on the Protection and Support of Breast Feeding. WHO/UNICEF . Aug 1990.

5. Hay WW, Jr, Levin MJ, Sondheiner JM, Deterding RR. Current Diagnosis and Treatment in Paediatrics. 2007. $18^{\text {th }}$ ed. New York: Lange Medical Books, McGraw Hill, 297-299.

6. Guyton AC. Textbook of Medical Physiology. $8^{\text {th }} \mathrm{ed}$. Philadelphia, USA: WB Saunders Company; 1991: 494.

7. Negrel AD, Thylefors B. The global impact of eye injuries. Ophthalmic Epidemiology 1998; 5(3): 143-169.

8. Mselle J. Visual impact of using traditional medicine on the injured eye in Africa. World Health Forum 1994; 15(2): 138-43.

9. Prajna VN, PIllai MR, Manimegalai TK, SRinivasan MI. Use of traditional eye medicines by corneal ulcer patients presenting to a hospital in South India. Indian J Ophthalmol 1999; 47: 15-18.

10. Afolabi OA, Grissom FE, Ako-Nai K, Torimiro SEA, Oke OL, Littleton GK. A preliminary survey of aerobic bacteria in breast milk of mothers from the low-income group in Nigeria. Tropical and Geographical Medicine 1985; 37: 245-249.

11. Van de Perre P, Simonon A, Msellati et al. Postnatal transmission of Human Immunodeficiency Virus type 1 from mother to infant: A prospective cohort study in Kigali, Rwanda. NEJM 1991; 325: 593-8.

12. Garg S, Jampol L. Systemic and intraocular manifestations of the West Nile Virus infection. Survey of Ophthalmology 2005; 50(1): 3-13.

13. Osahon AI. Consequences of traditional eye medication in UBTH, Benin City. Nig J Ophthalmology 1995; 51-54.

14. Ukponmwan CU. Corneal Ulcers in Benin City, Nigeria.Afr J Med Pract 2000; 7: 38- 45.

15. Courtright P, Lewallan S, Kanjaloti S, Divala DJ. Traditional eye medicine use among patients with corneal disease in rural Malawi. Br J Ophthalmol 1994; 78: 810-12.

16. Lewallan $S$, Courtright P. Peripheral corneal ulcers associated with use of African traditional eye medicines. Br J Ophthalmol 1995; 79: 343-46.

17. McMoli TE, Bordoh AN, Manube GMR, Bell EJ. Epidermic acute haemorrhagic conjunctivitis in Lagos, Nigeria. $\mathrm{Br} J$ Ophthalmol 1984; 68: 401-4.

18. Chirambo MC, Ben Ezra D. Causes for blindness among students in blind school institutions in a developing country. Br J Ophthalmol 1976; 60: 665-8.

19. Yorston D, Forster A. Traditional eye medicines and corneal ulceration in Tanzania. J of Trop Med Hygiene 1994; 97: 211-14. 